\title{
ERRATUM
}

Michael J. MacLellan • Aftab E. Patla

\section{Adaptations of walking pattern on a compliant surface to regulate dynamic stability}

Published online: 18 May 2006

(C) Springer-Verlag 2006

\section{Exp Brain Res (2006) DOI 10.1007/s00221-006-0399-5}

Unfortunately, a wrong graph of Fig. 7a was submitted to the article. The correct figure is presented here.

Therefore, the following information is not correct and should read as follows:

In the section "Stability margin" on page 6:

Line 4: " $\left(F_{(4,28)}=8.74, \quad P<0.0001\right) "$ should read “ $\left(F_{(4,28)}=10.91, P<0.0001\right) . "$

Line 7: "and significantly smaller in $\mathrm{FC}_{N+3}$ " should be deleted.
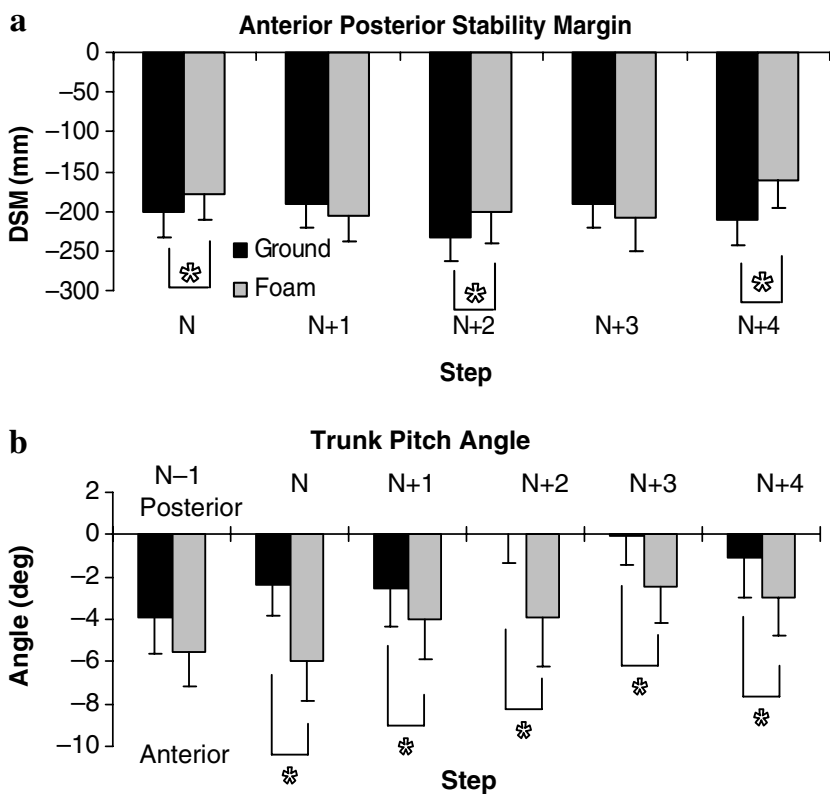

Fig. 7 a Stability margin in the anterior-posterior direction. b Estimated three-dimensional trunk pitch angles at each foot contact. Significant differences are denoted by *
The online version of the original article can be found at http:// dx.doi.org/10.1007/s00221-006-0399-5

M. J. MacLellan · A. E. Patla ( $\square)$

Gait and Posture Laboratory, Department of Kinesiology,

University of Waterloo, 200 University Ave. West,

Waterloo, ON, Canada N2L 3G1

E-mail: patla@healthy.uwaterloo.ca

Tel.: + 1-519-8884567 